\title{
Intestinal helminths of raccoon dogs ( $N$ yctereutes procyonoides) and red foxes (Vulpes vulpes) from the Augustów Primeval Forest (north-eastern Poland)
}

\author{
Jacek Karamon ${ }^{1}$, Małgorzata Samorek-Pieróg ${ }^{1}$, Bożena Moskwa ${ }^{2}$, \\ Mirosław Różycki ${ }^{1}$, Ewa Bilska-Zając ${ }^{1}$, \\ Jolanta Zdybel $^{1}$, Magdalena Włodarczyk ${ }^{1}$ \\ ${ }^{1}$ Department of Parasitology and Invasive Diseases, \\ National Veterinary Research Institute, 24-100 Pulawy, Poland \\ ${ }^{2} \mathrm{~W}$. Stefanski Institute of Parasitology, \\ Polish Academy of Sciences, 00-818 Warsaw, Poland \\ j.karamon@piwet.pulawy.pl
}

Received: June 7, 2016

Accepted: September 5, 2016

\begin{abstract}
Introduction: The aim of the study was to determine the prevalence of intestinal helminths in red foxes (Vulpes vulpes) and raccoon dogs (Nyctereutes procyonoides) in the Augustów Primeval Forest (north-eastern Poland), with particular regard to zoonotic parasites. Material and Methods: Intestines from 53 raccoon dogs and 66 red foxes were examined with the use of sedimentation and counting technique (SCT). Samples of faeces from 51 red foxes and 50 raccoon dogs were examined with the use of flotation method. Results: Parasitic helminths were found by SCT in $98.5 \%$ of red foxes and $96.2 \%$ of raccoon dogs. Both species were infected with: Alaria alata (93.9\% and 94.3\%, respectively), hookworms $(68.2 \%$ and $83.0 \%)$, Apophallus spp. (7.6\% and 15.1\%), Mesocestoides spp. (57.6\% and 24.5\%), Taenia spp. (40.9\% and 1.9\%), and Toxocara/Toxascaris nematodes (33.3\% 15.1\%). Echinococcus multilocularis was detected only in red foxes (6.1\%), but trematodes Echinostomatidae and nematodes Molineus spp. only in raccoon dogs (18.9\% and 41.5\%, respectively). Additionally, Capillaria spp. eggs were detected by flotation method in $78.4 \%$ of foxes and $20.0 \%$ of raccoon dogs. Conclusion: The study showed a very high percentage of red foxes and raccoon dogs infected with intestinal helminths in the Augustów Primeval Forest. Moreover, dangerous zoonotic parasites also were found, which should be taken into consideration in the assessment of infection risk for humans in this region.
\end{abstract}

Keywords: red foxes, raccoon dogs, parasites, Augustów Primeval Forest, Poland.

\section{Introduction}

The Augustów Primeval Forest is a large forest complex located in north-eastern Poland and partially in Lithuania and Belarus. The whole forest covers about $1600 \mathrm{~km}^{2}$, with more than $70 \%$ located in Poland. This area includes Wigry National Park and selected protected zones (nature reserves). Its environmental values make the Augustów Primeval Forest especially attractive for tourists. The forests are a home to many species of animals, including hosts of zoonotic parasites which may pose a real threat to people visiting this area. Red foxes (Vulpes vulpes) and raccoon dogs (Nyctereutes procyonoides) can be the final hosts of such dangerous zoonotic parasites as Echinococcus multilocularis or Toxocara spp. Most available data concerning red fox parasites focus only on $E$ multilocularis (4, 5, 11, 12, 16, 17, 23) while some also concern other parasites $(2,6,22)$. The recent study in Podlasie Province, the location of the Augustów Primeval Forest, has shown a relatively high prevalence of this parasite in red foxes (34\%) (11). 
However, data on helminths of raccoon dogs in Poland are very scarce. There is a study concerning the presence of E. multilocularis in this species in Poland (two positive animals from 25 examined) (15); furthermore, parasite infections of both species were described in the countries bordering on the Augustów Primeval Forest $(7,26,27)$.

Thus the aim of the study was to determine the prevalence of intestinal helminths in red foxes and raccoon dogs in the area of the Augustów Primeval Forest with particular regard to zoonotic parasites.

\section{Material and Methods}

The investigations were carried out in the area of the Augustów Primeval Forest located in the north-east of Poland (Fig. 1). The study involved 53 raccoon dogs (Nyctereutes procyonoides) (23 females and 30 males) and 66 red foxes (Vulpes vulpes) (30 females and 36 males) hunted in the 2014-2015 season. Their small and large intestines were sampled and frozen for at least seven days at $-80^{\circ} \mathrm{C}$ before examination to inactivate the tapeworm eggs (9). The intestines were examined with the use of the sedimentation and counting technique (SCT) according to the OIE Manual (20) adapted from the previously described method (10, 24). Moreover, samples of faeces (1-5 g) were collected from distal part of the rectum (51 red foxes and 50 raccoon dogs) and examined with the use of McMaster flotation method with Raynaud modification (25).

Statistical analysis. Confidence interval concerning the percentages of infected animals were calculated according to the method described by Newcombe (19). Differences in the prevalence of the parasites between red foxes and raccoon dogs were investigated using chi-square tests and a chi-squared test with Yate's continuity correction (at significance level 0.05). Statistical analyses were performed using Statistica 9.1 (StatSoft Inc., USA).

\section{Results}

Parasitic helminths were found in $96.2 \%$ of raccoon dogs and $98.5 \%$ of red foxes. Detailed results concerning SCT analysis are presented in Table 1. Eight different types of parasites were identified in raccoon dogs and seven in red foxes. Six types of helminths were found in both hosts: Alaria alata, Apophallus spp., Taenia spp., Mesocestoides spp., Toxocara/Toxascaris, and hookworms. However, Echinococcus multilocularis was detected only in red foxes (6.1\%), whereas Echinostomatidae flukes and Molineus spp. only in raccoon dogs (18.9\% and $41.5 \%$, respectively).

Alaria alata was highly prevalent in red foxes and raccoon dogs (93.9\% and 94.3\%, respectively). Both species were also infected at a similar rate (no significant differences) by hookworms $(68.2 \%$ and $83.0 \%)$ and flukes from Apophallus genus (7.6\% and 15.1\%). Mesocestoides spp. (57.6\%), Taenia spp. (40.9\%), and Toxocara/Toxascaris nematodes (33.3\%) were relatively highly prevalent in red foxes, while in raccoon dogs the prevalence was significantly lower $(24.5 \%, 1.9 \%$ and $15.1 \%$, respectively). There were no statistically significant differences in the occurrence of the parasites between males and females.

Few animals were infected with one type of parasite only $(5.7 \%$ of raccoon dogs and $4.6 \%$ of red foxes). Co-infections occurred in the majority of the animals studied (Fig. 2). Two types of parasites were simultaneously observed most frequently in raccoon dogs $(34.0 \%)$ and three - in red foxes $(43.9 \%)$.

Examination of faeces by flotation method allowed for detection of six types of parasites in red foxes and four in raccoon dogs (Table 2). In fox faeces Capillaria spp. eggs were most frequently found. Moreover, Trematoda, Toxocara spp., Taenidae, Mesocestoides spp., and hookworm eggs were also found in this species. Raccoon dog faeces contained: Trematoda, Capillaria spp., Toxocara spp. and hookworm eggs.

Table 1. Prevalence and intensity of helminths in red foxes and raccoon dogs in the Augustów Primeval Forest, Poland

\begin{tabular}{|c|c|c|c|c|}
\hline & \multicolumn{2}{|c|}{ Red foxes $(n=66)$} & \multicolumn{2}{|c|}{ Raccoon dogs $(n=53)$} \\
\hline & $\begin{array}{l}\text { Prevalence }(\%) \\
(95 \% \mathrm{CI})\end{array}$ & Intensity (CV\%) & $\begin{array}{l}\text { Prevalence }(\%) \\
(95 \% \mathrm{CI})\end{array}$ & Intensity (CV\%) \\
\hline Alaria alata & $93.9(85.4-97.6)$ & $113.0(117.0)$ & $94.3(84.6-98.1)$ & $1070.5(144.0)$ \\
\hline Echinostomatidae & - & - & $18.9(10.6-31.4)$ & $15.9(47.1)$ \\
\hline Apophallus spp. & $7.6(3.3-16.5)$ & $2.4(23.5)$ & $15.1(7.9-27.1)$ & $4.4(38.2)$ \\
\hline Echinococcus multilocularis & $6.1(2.4-14.6)$ & $104.0(27.3)$ & - & - \\
\hline Taenia spp. & $40.9 *(29.9-53.0)$ & $11.6(146.0)$ & $1.9 *(0.3-10.0)$ & $11.0(11.9)$ \\
\hline Mesocestoides spp. & $57.6^{*}(45.6-68.8)$ & $49.4(92.4)$ & $24.5 *(14.9-37.6)$ & $28.6(83.0)$ \\
\hline Toxocara/Toxascaris & $33.3 *(23.2-45.3)$ & $4.7(64.9)$ & $15.1 *(7.9-27.1)$ & $1.1(33.4)$ \\
\hline Hookworms & $68.2(56.2-78.2)$ & $7.3(113.0)$ & $83.0(70.8-90.8)$ & $12.4(110.2)$ \\
\hline Molineus spp. & - & - & $41.5(29.3-54.9)$ & $58.1(170.4)$ \\
\hline
\end{tabular}

*Significant difference of prevalence of the parasite between red foxes and raccoon dogs $(\mathrm{P}<0.05)$ 


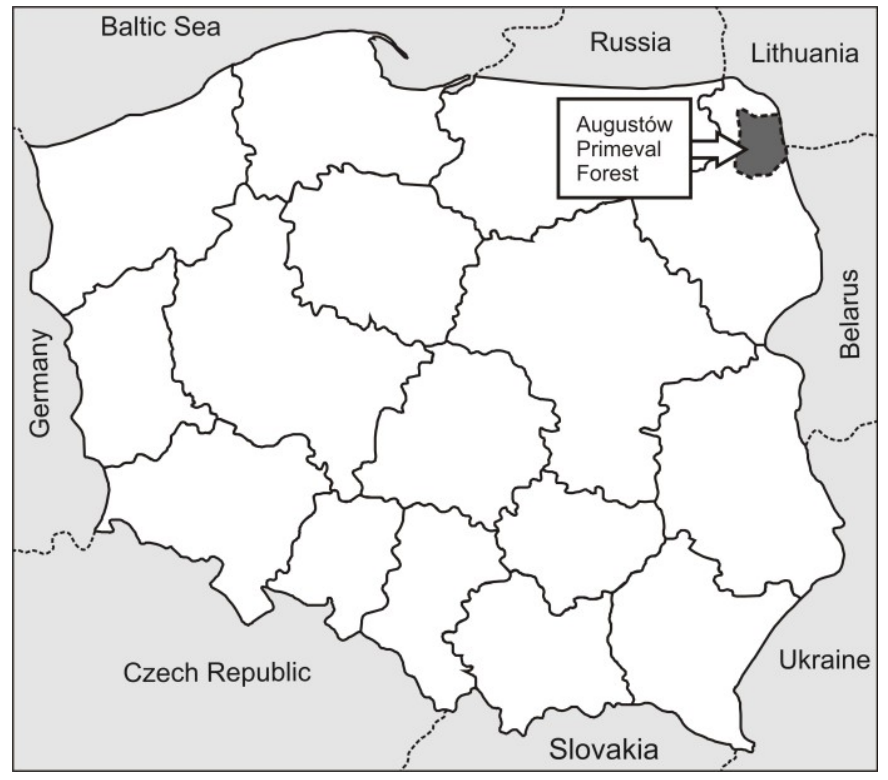

Fig. 1. Location of the Augustów Primeval Forest in Poland

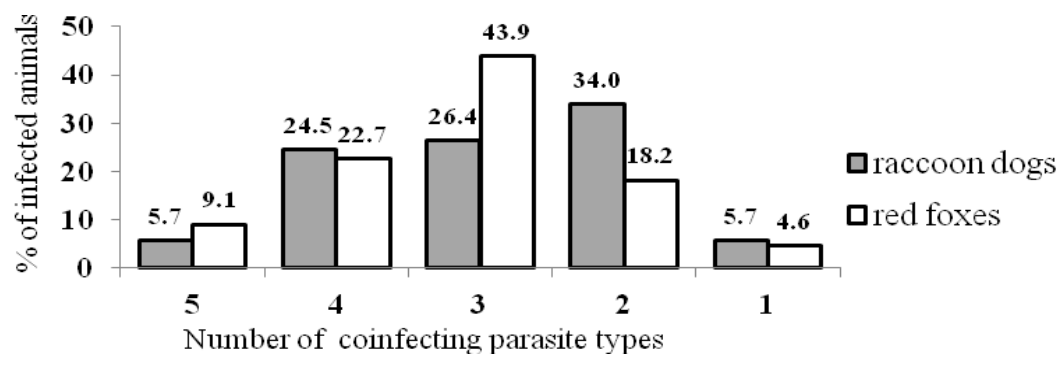

Fig. 2. Percentages of animals co-infected with different numbers of parasite types

Table 2. Results of flotation method examination of red foxes and raccoon dogs

\begin{tabular}{lllll}
\hline & \multicolumn{3}{c}{ Red foxes $(\mathrm{n}=51)$} & \multicolumn{2}{c}{ Raccoon dogs $(\mathrm{n}=50)$} \\
\cline { 2 - 5 } & $\begin{array}{l}\text { Percentage of positive samples } \\
(95 \% \mathrm{CI})\end{array}$ & $\begin{array}{l}\text { EPG } \\
(\mathrm{CV} \%)\end{array}$ & $\begin{array}{l}\text { Percentage of positive samples } \\
(95 \% \mathrm{CI})\end{array}$ & $\begin{array}{l}\text { EPG } \\
(\mathrm{CV} \%)\end{array}$ \\
\hline Trematoda & $64.7(50.1-76.4)$ & $831.5(249.4)$ & $56.0(42.3-68.8)$ & $507.8(286.4)$ \\
Taeniidae & $9.8(4.3-21.0)$ & $2126.0(220.2)$ & - & - \\
Mesocestoides spp. & $7.8(3.1-18.5)$ & $36.3(117.2)$ & - & - \\
Hookworms & $5.9(2.0-15.9)$ & $113.3(68.5)$ & $2.0(0.4-10.5)$ & $600.0(-)$ \\
Toxocara spp. & $25.5(15.6-38.9)$ & $247.5(158.4)$ & $4.0(1.1-13.5)$ & $18.5(87.9)$ \\
Capillaria spp. & $78.4(65.4-87.5)$ & $416.4(237.2)$ & $20.0(11.2-33.0)$ & $496.7(276.6)$ \\
\hline
\end{tabular}

\section{Discussion}

The study demonstrated a very high percentage of red foxes and raccoon dogs infected with intestinal helminths in the Augustów Primeval Forest. No parasites were found in few animals (one red fox and two raccoon dogs). Most animals were simultaneously infected with two, three, or four parasite species. Similarly high prevalence of infected red foxes (about 90\%) was found in Lublin Province (eastern Poland) (13), in central Poland (94.5\%) (6), in western Poland (79\%) (2), and in Lower Silesia Province (south- western Poland) (91\%) (22). However, during the investigation limited to the Lower Silesian Forest only $34 \%$ of red foxes were infected with parasites (3).

Our study confirmed the occurrence of the most dangerous zoonotic parasite E. multilocularis in red foxes in the area of the Augustów Primeval Forest. However, the prevalence $(6.1 \%)$ was significantly lower than the mean prevalence in the Podlasie Province $(34.0 \%)$ estimated a few years ago (11). It shows a non- homogenous distribution of this infection in the province. On the other hand, in Lithuania, bordering on the investigated area, the prevalence was 
very high $(58.7 \%)(7)$, similarly as in other Baltic countries $(1,18)$. It is regarded that in the same area, generally, the prevalence of this tapeworm in raccoon dogs was even several times lower than in red foxes (21). Therefore, the lack of E. multilocularis positive raccoon dogs in the Augustów Primeval Forest along with its relatively low prevalence in red foxes was not surprising. Lower E. multilocularis prevalence (or absence) in raccoon dogs compared to red foxes was found in Baltic countries $(1,7,14,18)$ and in Belarus $(26,27)$. The only available data about parasites of raccoon dogs in Poland was presented in the study concerning E. multilocularis $-8 \%$ of these animals from the Pomerania Province (northern Poland) were infected (15). Differences in the prevalence between red foxes and raccoon dogs (similarly to E. multilocularis) were also observed in the case of rodent-transmitted Taenia tapeworms (7, 26, 27). It was explained by different feeding and hunting behaviour (7). In our study, the Taenia genus was not differentiated by individual species. However, the significantly higher prevalence of Taenia spp. in red foxes $(40.9 \%)$ in comparison to raccoon dogs $(1.9 \%)$ suggests that these were mainly rodenttransmitted Taenia species. Moreover, Toxocara and Mesocestoides were also significantly more frequently found in red foxes, confirming the results regarding the area of the bordering countries $(7,26,27)$. The high percentage of red foxes infected with the species mentioned above was also noted in earlier investigations in other regions of Poland $(2,6,13,22)$.

The most frequently occurring parasite in both animal species was Alaria alata (nearly $100 \%$ of all animals were infected). Similarly high prevalence in red foxes and raccoon dogs in Lithuania was detected by Bruzinskite-Schmidhalter et al. (7). High percentage of red foxes infected with Alaria alata was also found in central-eastern Poland $(6,13)$ but in other regions (western provinces) these flukes were relatively rarely noted $(2,3,22)$. It was probably connected with different environmental conditions and access to intermediate hosts.

In the Augustów Primeval Forest the nematode found only in raccoon dogs was Molineus spp., in relatively high percentage $(41.5 \%)$. In Belarus this species was detected $(26,27)$ in both red foxes and raccoon dogs but in lower percentage (3.2\% and 3.9\%). However, in Slovenia about $30 \%$ of red foxes were infected with this parasite (28).

Echinostomatidae flukes were the only parasites found exclusively in raccoon dogs. The proportions in the prevalence of this parasite in raccoon dogs and red foxes were described in Lithuania $(10 \%$ of raccoon dogs and $1.5 \%$ of red foxes) (7); the differences were probably connected with different dietary habits.

The coproscopical examination of red foxes and raccoon dogs revealed Capillaria eggs. It is highly probable that there were eggs of Capillaria aerophila (syn. Eucoleus aerophilus) - whose adult worms are located in the respiratory tract. A high percentage of positive samples from red foxes $(78 \%)$ and almost fourtimes lower in raccoon dogs $(20 \%)$ correlated with the results concerning $C$. aerophila obtained in Lithuania (7). High prevalence of these lung worms was also found in Norway (8).

Summing up, the investigation demonstrated very high level of intestinal helminth infections in raccoon dogs and red foxes in the Augustów Primeval Forest. Zoonotic parasites were also found, including very dangerous E. multilocularis, which should be taken into consideration in the assessment of infection risk for humans in this region.

Conflict of Interests Statement: The authors declare that there is no conflict of interests regarding the publication of this article.

Financial Disclosure Statement: The raccoon dogs and red foxes carcasses were obtained in the frame of project: „Active protection of lowland populations of capercaillie in the Bory Dolnośląskie Forest and Augustów Primeval Forest" (LIFE11 NAT/PL/428) by the European Commission, the National Fund for Environmental Protection and Water Management and the Polish State Forests.

Animal Rights Statement. None required.

\section{References}

1. Bagrade G., Snabel V., Romig T., Ozolins J., Huettner M., Miterpakova M., Sevcova D., Dubinsky P.: Echinococcus multilocularis is a frequent parasite of red foxes (Vulpes vulpes) in Latvia. Helminthologia 2008, 45, 157-161.

2. Balicka-Ramisz A., Ramisz A., Pilarczyk B., Bienko R.: Fauna of gastro-intestinal parasites in red foxes in Western Poland. Med Weter 2003, 59, 922-925.

3. Binkowski L.J., Merta D., Przystupinska A., Soltysiak Z., Pacon J., Stawarz R.: Levels of metals in kidney, liver and muscle tissue and their relation to the occurrence of parasites in the red fox in the Lower Silesian Forest in Europe. Chemosphere 2016, 149, 161-189.

4. Borecka A., Gawor J., Malczewska M., Malczewski A.: Occurence of Echinococcus multilocularis in red foxes (Vulpes vulpes) in southern Poland. Helminthologia 2008, 45, 24-27.

5. Borecka A., Gawor J., Malczewska M., Malczewski A.: Prevalence of Echinococcus multilocularis tapeworm in red foxes in central Poland. Med Weter 2007, 63, 1333-1335.

6. Borecka A., Gawor J., Malczewska M., Malczewski A.: Prevalence of zoonotic helminth parasites of the small intestine in red foxes from central Poland. Med Weter 2009, 65, 33-35.

7. Bruzinskaite-Schmidhalter R., Sarkunas M., Malakauskas A., Mathis A., Torgerson P.R., Deplazes P.: Helminths of red foxes (Vulpes vulpes ) and raccoon dogs (Nyctereutes procyonoides) in Lithuania. Parasitology 2012, 139, 120-127.

8. Davidson R.K., Gjerde B., Vikoren T., Lillehaug A., Handeland K.: Prevalence of Trichinella larvae and extra-intestinal nematodes in Norwegian red foxes (Vulpes vulpes). Vet Parasitol 2006, 136, 307-316.

9. Eckert J., Deplazes P., Craig P.S., Gemmell M.A., Gottstein B., Heath D., Jenkins D.J., Kamiya M., Lightowlers M.: Echinococcosis in animals: clinical aspects, diagnosis and treatment. In: WHO/OIE Manual on Echinococcosis in Humans 
and Animals: A Public Health Problem of Global Concern, edited by J. Eckert, M.A. Gemmell, F.X. Meslin and Z.S. Pawlowski, World Organisation for Animal Health, Paris, France, 2001, pp. 72-99.

10. Hofer S., Gloor S., Muller U., Mathis A., Hegglin D., Deplazes P.: High prevalence of Echinococcus multilocularis in urban red foxes (Vulpes vulpes) and voles (Arvicola terrestris) in the city of Zurich, Switzerland. Parasitology 2000, 120, $135-142$.

11. Karamon J., Kochanowski M., Sroka J., Cencek T., Różycki M., Chmurzyńska E., Bilska-Zając E.: The prevalence of Echinococcus multilocularis in red foxes in Poland - current results (2009-2013). Parasitol Res 2014, 113, 317-322.

12. Karamon J., Sroka J., Cencek T., Michalski M.M., Zięba P., Karwacki J.: Prevalence of Echinococcus multilocularis in red foxes in two eastern provinces of Poland. Bull Vet Inst Pulawy 2011, 55, 429-433.

13. Karamon J., Ziomko I.: Intestinal helminthofauna of red foxes in Lubelskie Province, with particular regards ro Echinococcus multilocularis. $13^{\text {th }}$ Congress of Polish Society of Veterinary Sciences, Olsztyn, 2008, pp. 170-171.

14. Laurimaa L., Sueld K., Davison J., Moks E., Valdmann H., Saarma U.: Alien species and their zoonotic parasites in native and introduced ranges: The raccoon dog example. Vet Parasitol 2016, 219, 24-33.

15. Machnicka-Rowińska B., Rocki B., Dziemian E., KolodziejSobocinska M.: Raccoon dog (Nyctereutes procyonoides) the new host of Echinococcus multilocularis in Poland. Wiad Parazytol 2002, 48, 65-68.

16. Malczewski A., Gawor J., Malczewska M.: Infection of red foxes (Vulpes vulpes) with Echinococcus multilocularis during the years 2001-2004 in Poland. Parasitol Res 2008, 103, 501-505.

17. Malczewski A., Rocki B., Ramisz A., Eckert J.: Echinococcus multilocularis (Cestoda), the causative agent of alveolar echinococcosis in humans - first record in Poland. $\mathrm{J}$ Parasitol 1995, 81, 318-321.

18. Moks E., Saarma U., Valdmann H.: Echinococcus multilocularis in Estonia. Emerg Infect Dis 2005, 11, 1973-1974.
19. Newcombe R.G.: Two-sided confidence intervals for the single proportion: comparison of seven methods. Stat Med 1998, 17, 857-872.

20. OIE: Echinococcosis/hydatidosis. In: Manual of Diagnostic Tests and Vaccines for Terrestrial Animals, edited by Office International des Epizooties, Paris, France, 2008, pp. 175-189.

21. Oksanen A., Siles-Lucas M., Karamon J., Possenti A., Conraths F., Romig T., Deplazes P., Wysocki P., Mannocci A., Malpartini D., Moffongelli E., La Torre G., Casull A.: The geographical distribution and prevalence of Echinococcus multilocularis in animals and the importance of the different host species in the life cycle of this parasite in the European Union (EU) and adjacent countries: a systematic review. Parasit Vect 2016, (in press).

22. Pacon J., Soltysiak Z., Nicpon J., Janczak M.: Prevalence of internal helminths in red foxes (Vulpes vulpes) in selected regions of Lower Silesia. Med Weter 2006, 62, 67-69.

23. Ramisz A., Eckert J., Balicka-Ramisz A., Grupiński T., Pilarczyk B., Krol-Pospieszny A., Slowikowski P.: Prevalence of Echinococcus multilocularis in foxes in the Western Poland. Med Weter 1997, 53, 340-342.

24. Rausch R.L., Fay F.H., Williamson F.S.L.: The ecology of Echinococcus multilocularis (Cestoda, Taeniidae) on St. Lawrence Island, Alaska .2. Helminth populations in the definitive host. Ann Parasitol Hum Comp 1990, 65, 131-140.

25. Raynaud J.P.: Etude de l'efficacite d;une technique de coproscopie quantitative pour le diagnostic de routine et le controle des infestations parasitaires des bovins, ovins, equins et porcins. Ann Parasitol Hum Comp 1970, 45, 321-342.

26. Shimalov V.V., Shimalov V.T.: Helminth fauna of the racoon dog (Nyctereutes procyonoides Gray, 1834) in Belorussian Polesie. Parasitol Res 2002, 88, 944-945.

27. Shimalov V.V., Shimalov V.T.: Helminth fauna of the red fox (Vulpes vulpes Linnaeus, 1758) in southern Belarus. Parasitol Res 2003, 89, 77-78

28. Vergles Rataj A., Posedi J., Zele D., Vengust G.: Intestinal parasites of the red fox (Vulpes vulpes) in Slovenia. Acta Vet Hung 2013, 61, 454-462. 